\title{
Recruitment of New Osteoblasts and Osteoclasts Is the Earliest Critical Event in the Pathogenesis of Human Multiple Myeloma
}

\author{
Régis Bataille," Daniel Chappard," Christian Marcelli," Philippe Dessauw," Pierre Baldet," \\ Jacques Sany, ${ }^{*}$ and Christian Alexandre* \\ *Immuno-Rhumatologie and Institut National de la Santé et de la Recherche Médicale U291, Centre Gui-de-Chauliac, Hôpital Saint- \\ Eloi, 34059 Montpellier Cedex, France; ${ }^{\ddagger}$ Laboratoire de Biologie du Tissu Osseux, Faculté de Médecine, 42023 Saint-Etienne \\ Cedex 2, France; and ${ }^{\S}$ Laboratoire d'Anatomie Pathologique, Hôpital Lapeyronie, 34059 Montpellier Cedex, France
}

\begin{abstract}
Considering the special relation of human multiple myeloma (MM) to bones, it is of importance to clarify the early steps of bone involvement in this disease. In this work, using bone histomorphometry (including histoenzymologic and kinetic studies for the first time), we have evaluated the bone remodeling (i.e., bone resorption and bone formation rates) of 16 individuals with early MM in comparison with that of 10 with benign monoclonal gammopathy (BMG) and that of 17 patients with previously untreated overt MM. A significantly increased osteoblastic recruitment was observed in the individuals with early MM when compared with those with $B M G(P<0.01)$. A significant $(P<0.01)$ increased bone resorption (i.e., eroded surfaces, osteoclast numbers and surfaces) was observed from the early stage of MM in comparison with the BMG status where bone resorption remained within the normal range. At the tissue level, there was no difference in terms of bone resorption between early and overt MM. On the other hand, osteoblast activity was significantly reduced in patients with overt MM (P $<0.05$ by comparison with those with early MM).

A significant enhancement of osteoblastic recruitment with an increased generation of new osteoclasts is an early critical event in the pathogenesis of human MM. Of particular importance is the early stimulation of osteoblasts, since these cells produce high amounts of IL-6, a potent myeloma cell growth factor and a critical cytokine for the formation of osteoclasts in the bone marrow. (J. Clin. Invest. 1991. 88:62-66.) Key words: multiple myeloma $\bullet$ early bone remodeling
\end{abstract}

\section{Introduction}

Bone involvement, bone destruction mainly, is a common feature of patients with overt multiple myeloma (MM), ${ }^{1}$ in con-

Address correspondence to Dr. Régis Bataille, Institut National de la Santé et de la Recherche Médicale U291, Centre Gui-de-Chauliac, Hôpital Saint-Eloi, 34059 Montpellier Cedex, France.

Received for publication 24 October 1990 and in revised form 7 February 1991.

1. Abbreviations used in this paper: BFR, bone formation rates; BMG, benign monoclonal gammopathy; BS, bone surface referent; BV, bone volume referent; MGUS, monoclonal gammopathy of undetermined significance; MM, multiple myeloma; TNF, tumor necrosis factor; TRAP, tartrate-resistant acid phosphatase; TV, tissue volume referent.

J. Clin. Invest.

(c) The American Society for Clinical Investigation, Inc.

0021-9738/91/07/0062/05 \$2.00

Volume 88, July 1991, 62-66 trast to what is observed in other B cell malignancies $(1,2)$. Bone involvement is related to an excessive bone resorption encountered in the close vicinity of myeloma cells (3-6). This increased resorption is due to the local stimulation of osteoclasts by soluble factors released by myeloma cells and environmental cells, such as IL-1 and tumor necrosis factor (TNF) (3, 7-13). The severity of lytic bone lesions is actually correlated with the presence of a marked uncoupling process in patients with advanced MM: increased bone resorption with decreased bone formation (14). Patients lacking lytic bone lesions and rare osteosclerotic variants have an opposite osteoblastic presentation (15).

Considering the special relation of myeloma cells to bone, it is of critical importance to clarify the early steps of bone involvement in this disease. In this work, we have evaluated the bone remodeling of individuals with early $\mathbf{M M}$ in comparison with those of patients with previously untreated overt MM and of individuals with benign monoclonal gammopathy (BMG). Our new histoenzymologic and kinetic studies show that a strong stimulation of osteoblastic recruitment with an increased generation of new osteoclasts is an early critical event in the pathogenesis of human MM. Of particular importance is the early stimulation of osteoblasts we have found, since these cells produce high amounts of IL-6 (16), a potent myeloma cell growth factor $(17,18)$.

\section{Methods}

\section{Patients}

Bone histomorphometry was performed in 10 individuals with BMG, 16 with early MM, and in 17 patients with overt MM. In individuals with either BMG or early MM, bone histomorphometry was performed at the time of the first investigation, these individuals being referred as monoclonal gammopathy of undetermined significance (MGUS [19]). In these cases of MGUS, the subsequent follow-up with or without the occurrence of an overt MM allowed a restaging of MGUS to be done as it is either for BMG or early MM. Complete histoenzymologic studies of osteoclasts are available in $10 \mathrm{BMG}$ and 12 early MM and complete kinetic studies of osteoblasts in 6 BMG and 16 early MM. Identical investigations were performed in previously untreated patients with overt MM. Histoenzymologic studies are available in 17 patients and kinetic studies in 14 cases.

\section{BENIGN MONOCLONAL GAMMOPATHY}

10 individuals with MGUS were retrospectively included in the current study as BMG. There were nine IgG cases and one IgA and the sex ratio $\mathrm{M} / \mathrm{F}$ was 1 . As previously emphasized, none of these individuals developed overt MM, with a minimal follow-up of $3 \mathrm{yr}$. This does not exclude the possible occurrence of overt MM beyond $3 \mathrm{yr}$, as observed by many investigators (19). The definition of these cases has been previously published $(20,21)$. 


\section{EARLY MULTIPLE MYELOMA}

16 individuals with MGUS were retrospectively included in the current study as early MM. There were eight IgG MM, six IgA, and only two Bence Jones. The sex ratio $M / F$ was 1.10 . As previously emphasized, these individuals developed overt MM 3-12 mo after the first clinical evaluation. All these individuals had normal hemoglobin, and serum calcium, creatinine, and beta-2-microglobulin levels. They did not present any lytic bone lesions on radiography. The median monoclonal IgG and $\mathrm{IgA}$ serum levels were $2.7 \mathrm{~g} / \mathrm{dl}$ (range $2.2-5.4 \mathrm{~g} / \mathrm{dl}$ ) and $2.2 \mathrm{~g} / \mathrm{dl}$ (range $2.3-3.3 \mathrm{~g} / \mathrm{dl}$ ), respectively. On bone marrow swears, the median percentage of plasma cells was $14 \%$ (range $0-40 \%$ ). In the two individuals with Bence Jones only early MM, the monoclonal component in the urines was $<1 \mathrm{~g} /$ day.

\section{OVERT MULTIPLE MYELOMA}

17 patients with previously untreated overt $\mathrm{MM}$ were included in this study. The diagnostic criteria and the management of these patients have been previously described $(20,21)$. There were ten IgG MM, five IgA, and only two Bence Jones. The sex ratio $\mathrm{M} / \mathrm{F}$ was 1.05 .

\section{Bone histomorphometry}

Quantitative histology of bone changes was performed as previously described on undecalcified transiliac bone biopsy specimens $(5,14,15)$.

\section{BONE BIOPSIES}

Bone biopsies were performed by one operator of the investigative team under local anesthesia from a standardized point $2 \mathrm{~cm}$ below the iliac crest and $2 \mathrm{~cm}$ behind the anterosuperior iliac spine. The transiliac bone cores were $8 \mathrm{~mm}$ in diameter, according to Frost's recommendations (22). The specimens were immediately fixed in acidified $70 \%$ alcohol and were kept for $24 \mathrm{~h}$ at $4^{\circ} \mathrm{C}$. They were then dehydrated over a period of $36 \mathrm{~h}$ in pure acetone at $4^{\circ} \mathrm{C}$.

\section{BONE BIOPSY EMBEDDING AND STAINING PROCEDURES}

Biopsy specimens were embedded in a mixture of purified glycol and methyl methacrylates according to the laboratory methods described elsewhere (23). Infiltration of bone cores as well as the embedding process were done in a cold environment to preserve bone enzyme activities. $7 \mu \mathrm{m}$ in thickness sections were cut using a Jung type $\mathrm{K}$ microtome equipped with HK3 tungsten carbide knives. Stainings for routine histomorphometry were done by a modification of Goldner's procedures on eight nonserial sections (24). Six additional nonserial sections for histochemical identification of tartrate resistant acid phosphatase (TRAP, a histochemical procedure for osteoclasts) activity by a simultaneous coupling method using $\alpha$-naphtyl phosphate, fast violet $\mathrm{B}$, and L-(+)-sodium tartrate were done $(25,26)$.

HISTOMORPHOMETRIC ANALYSIS

Nomenclature, symbols, and units used in this study are those published recently in the report of the American Society for Bone and Mineral Research, Histomorphometry Nomenclature Committee; (27). Details on the main parameters used in this study have been outlined in the table.

Bone mass parameters. Bone volume (corresponding to the part of cancellous space occupied by trabecular bone), was measured on a Leitziast image analyzer (28).

Parameters of bone resorption. Measurements of osteoclastic parameters were made on a semiautomatic image analyzer system composed of a digitizing tablet (Summasketch; Summagraphics) connected to a microcomputer (Macintosh Plus). Microscopic observation was performed with a Leitz Diaplan microscope equipped with a drawing system (Camera Lucida). The analytic programs were developed in our laboratory $(29,30)$. Measurements were made with a magnification of 100 using a standard rectangular microphotographic eyepiece of known surface projected over the cancellous space. On Goldner's sections, we have measured eroded surfaces (\%). On TRAP-stained sections, only the positive cells in close contact with the calcified trabecular bone were taken into account as osteoclasts. The following parame- ters were measured: osteoclast number per square millimeter of section area and osteoclast surface (\%) (ex-active resorption surfaces). The reproducibility of the methods measuring the TRAP-positive cell count was previously evaluated $(20,26)$.

Parameters of bone formation. Patients received oral demethylchlortetracycline $(600 \mathrm{mg} / \mathrm{d})$ twice, with a $12-\mathrm{d}$ interval and the mean separation between labels was measured with a fluorescent microscope. The following parameters were evaluated: osteoid volumes (\%); osteoid surfaces (\%); osteoid thickness $(\mu \mathrm{m})$; mineral apposition rates $(\mu \mathrm{m} / \mathrm{d})$; single/double labeled surfaces (\%). Double labeled surfaces corresponding to the fractional surfaces involved in active mineralization (\%) over the whole labeling period were measured and used to calculate the following derived bone formation rates (BFR): BFR/BS (bone surface referent); BFR/BV (bone volume referent); and BFR/TV (tissue volume referent). As detailed in Table I, BFR expressed the volume of mineralized bone formed per unit time, reflected the recruitment of new osteoblasts to make osteoid and was expressed per unit of bone surface, bone volume, and tissue volume.

\section{Statistical analysis}

For statistical analyses, we have used the median test, the Wilcoxon sum rank test, and the Pearson coefficient correlation.

\section{Results}

Bone resorption. A significant increased bone resorption was observed from the stage of early MM in comparison with that of BMG $(P<0.01)$. This was illustrated by a significant increase in the percentages of eroded surfaces $(P<0.01$, Fig. 1$)$, of the osteoclast numbers $(P<0.01$, Fig. 2$)$ and of the osteoclast surfaces $(P<0.01$, data not shown). When compared with healthy individuals (26), 92\% of those with early MM presented an excessive bone resorption (i.e., eroded surfaces $>6 \%$, $3 \mathrm{SD}$ above the mean value of age-and sex-matched healthy individuals) whereas individuals with BMG generally retained normal bone resorption. At the tissue level, the parameters of bone resorption did not differ between early and overt MM (Figs. 1 and 2). Although there was a trend towards higher percentages of eroded surfaces in patients with higher numbers of osteoclasts, no direct correlation was found between these two parameters.

Bone formation. A strong stimulation of osteoblastic recruitment was observed in the individuals with early MM. As shown in Fig. 3, BFR in early MM were significantly greater than those of individuals with BMG $(P<0.01)$. The BFR included BFR/BS (Fig. 3), BFR/BV, and BFR/TV $(P<0.01$, data not shown), considering either single or double labeled surfaces. In comparison with healthy individuals, $74 \%$ of those with early MM presented a significant increase of BFR (i.e., $>0.020 \mathrm{~mm}^{3} / \mathrm{mm}^{2}$ per d). This BFR increase appeared mainly related to the recruitment of new osteoblasts. Indeed, the percentages of double labeled surfaces were found to be significantly higher in early $\mathrm{MM}$ than in individuals with BMG $(8.3 \pm 5.9$ vs. $1.4 \pm 1.1 \%, P<0.01)$ while mineral apposition rates (reflecting osteoblast activity at the cell level) did not differ significantly between early MM and BMG $(0.70 \pm 0.11$ vs. $0.64 \pm 0.13 \mu \mathrm{m} / \mathrm{d})$. These results were opposite to those found in patients with overt MM, where a depressed osteoblast activity was observed. This was illustrated by a significant reduction of BFR as compared to healthy individuals $(P<0.05)$. This reduction of BFR appeared related to both $(a)$ a decreased osteoblastic activity at the cell level illustrated by a significant reduction of mineral apposition rates in overt MM compared with 
Table I. Details on Bone Histomorphometry Standardization of Nomenclature, Symbols, and Units (from References 4 and 27)

\begin{tabular}{|c|c|c|c|}
\hline & Terminology & Abbreviation (units) & Definition \\
\hline \multirow[t]{3}{*}{ (A) Bone resorption } & Eroded surface & ES/BS (\%) & $\begin{array}{l}\text { Percentage of the total trabecular surfaces where marks } \\
\text { of a previous resorption were visible, whether } \\
\text { or not they contained osteoclasts (Oc) }\end{array}$ \\
\hline & Osteoclast number & $\operatorname{NOc}\left(n / \mathrm{mm}^{2}\right)$ & $\begin{array}{l}\text { Number of Oc, as TRAP-positive cells resorbing } \\
\text { bone surfaces }\end{array}$ \\
\hline & Osteoclast surface & OcS/BS (\%) & Percentage of ES containing Oc \\
\hline \multirow[t]{6}{*}{ (B) Bone formation } & Osteoid volume & OV/BV (\%) & Percentage of bone volume occupied by osteoid \\
\hline & Osteoid surface & OS/BS (\%) & Percentage of bone surfaces covered with osteoid seams \\
\hline & Osteoid thickness & OTh $(\mu m)$ & Osteoid thickness \\
\hline & Mineral apposition rate & $\operatorname{MAR}(\mu m / d)$ & $\begin{array}{l}\text { Distance between the midpoints or between the } \\
\text { corresponding edges of two consecutive labels divided by } \\
\text { the time between the midpoints of the labeling } \\
\text { periods }\end{array}$ \\
\hline & Single, double labeled surface & $\operatorname{sd} \operatorname{LS}(\%)$ & $\begin{array}{l}\text { Percentage of OS singly or doubly labeled with } \\
\text { antibiotics }\end{array}$ \\
\hline & $\begin{array}{l}\text { Bone formation rate } \\
\text { Bone surface referent } \\
\text { Bone volume referent } \\
\text { Tissue volume referent }\end{array}$ & $\begin{array}{l}\text { BFR } \\
\text { BFR/BS }\left(\mathrm{mm}^{3} / \mathrm{mm}^{2} \text { per } d\right) \\
\text { BFR/BV } \\
\text { BFR/TV }\end{array}$ & $\begin{array}{l}\text { Mineralized bone formation rate, i.e., the volume of } \\
\text { mineralized bone formed per unit time; reflects the } \\
\text { recruitment of new osteoblasts to make osteoid; can be } \\
\text { expressed per unit of bone surface (BFR/BS), of bone } \\
\text { volume (BFR/BV), and of tissue volume (BFR/TV). }\end{array}$ \\
\hline
\end{tabular}

those of early $\mathrm{MM}(0.59 \pm 0.16$ vs. $0.70 \pm 0.11 \mu \mathrm{m} / \mathrm{d}, P<0.05)$; and $(b)$ principally a marked reduction of the recruitment of new osteoblasts, illustrated by a significant reduction of double labeled surfaces in overt MM (3.3 \pm 4.1 vs. $8.3 \pm 5.9 \%$ in early MM, $P<0.05$ ).

Bone resorption and formation. When parameters of bone resorption (osteoclast surfaces, \%) and those of BFR were plotted together either in early MM or overt MM, a significant correlation was observed $(r=0.88, P=0.04$ in overt $\mathrm{MM}$; and $r=0.99, P=0.001$ in early MM).

\section{Discussion}

Bone involvement is a characteristic feature of MM. Until now, the studies have focused on the presence of an excessive bone resorption associated with a low bone formation in patients with advanced $\mathrm{MM}(4,5,14)$. Of importance, we have recently demonstrated that this uncoupling process was di-

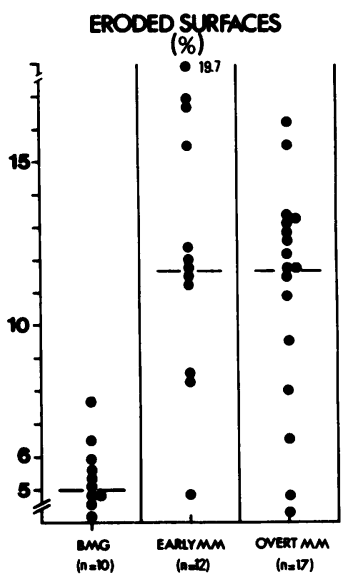

Figure 1. Percentages of eroded surfaces in individuals with BMG ( $n$ $=10)$, those with early $\mathrm{MM}(n=12)$, and patients with overt $\mathrm{MM}(n=17)$. BMG vs. early MM: $P<0.01$. Early MM vs. overt MM: no difference. rectly responsible for the lytic bone lesions in myeloma patients (14). As early as 1974 , soluble factors released by myeloma cells, i.e., osteoclast activating factors, were found to be involved in this osteoclast activation (3). Considering the special relation of myeloma cells to bones, it is of critical importance to clarify the early steps of bone involvement in this disease. Indeed, the mechanisms of early MM bone involvement could be close to those involved in MM development (i.e., oncogenesis, tumor growth). Thus, we have evaluated the bone remodeling of individuals with early $\mathrm{MM}$, in comparison with that of individuals with BMG and that of patients with previously untreated overt MM.

As previously reported by ourselves, bone remodeling was normal in individuals with BMG (5). On the other hand, an

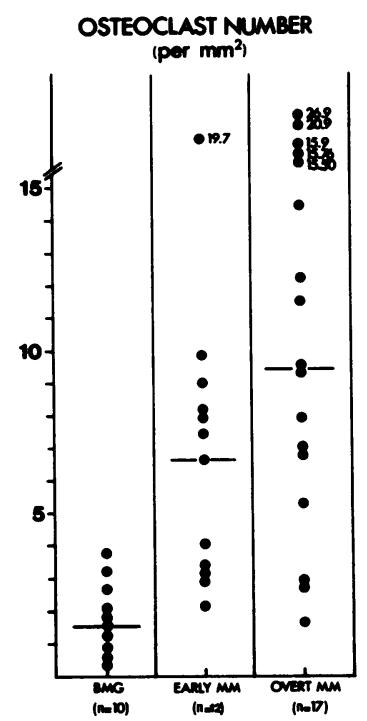

Figure 2. Numbers of osteoclasts per square millimeter of trabecular bone in individuals with BMG $(n=10)$, those with early MM $(n=12)$, and patients with overt MM $(n=17)$. BMG vs. early MM: $P<0.01$. Early MM vs. overt MM: no difference. 


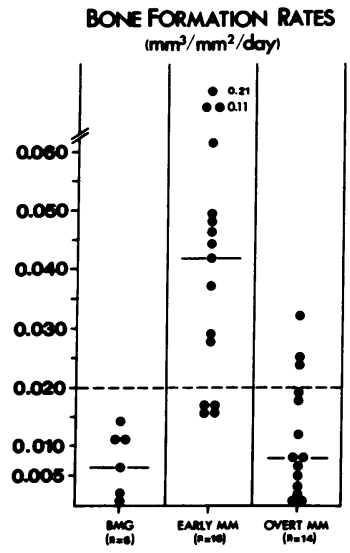

Figure 3. Bone formation rates (BFR/ BS [see Methods] $)\left(\mathrm{mm}^{3} / \mathrm{mm}^{2}\right.$ per d) in individuals with BMG $(n=6)$, those with early MM $(n=16)$, and patients with overt $\mathrm{MM}(n=14)$. BMG vs. early MM: $P<0.01$. Early MM vs. overt MM: $P<0.01$. Normal rates $<0.020$

abnormal bone remodeling was found in a majority of individuals with early MM. This finding is critical for the clinical evaluation of individuals with MGUS (19). As a matter of fact, it means that bone histomorphometry might be useful in MGUS evaluation to discriminate BMG from early MM, several weeks or even months before the occurrence of overt MM. A prospective study on a large number of cases of MGUS is on the way to definitely answering this question. Incidently, three individuals with BMG had a slight but significant increase in their percentages of eroded surfaces. A recent evaluation of these individuals has shown a significant increase of monoclonal protein levels $(30 \%)$ in the case having the highest bone resorption $(7.7 \%)$

In this study, we have demonstrated an increased bone resorption from the stage of early MM. More particularly, using histoenzymology we have demonstrated an increased formation of new osteoclasts that had never been done previously in early MM. Several cytokines with bone resorbing activity, such as IL-1, TNF, and IL-6 (31) which are present in the myeloma intermediate "milieu" $(11-13,17,18)$ and acting in cascade and synergy (32) are probably responsible for this early phenomenon. At the cell and tissue levels, this excessive bone resorption in early MM is as marked as that in overt MM. On the other hand, when the kinetic parameters of bone formation were considered, a striking difference was found between early and overt MM. In particular, a strong stimulation of osteoblastic recruitment was found in early MM. This was not observed in patients with overt MM. In these latter patients, except in those lacking lytic bone lesions (15), the parameters of bone formation were normal to low, especially in patients with advanced disease (14, and this study). In two patients recently evaluated by one of us (D. Chappard), where serial bone biopsies were available, the progression from the early to the overt stages of the disease was marked by a significant increase of both the percentages of eroded surfaces and the osteoclast numbers and by a significant decrease of BFR (D. Chappard, personal data). The observation of a strong osteoblastic recruitment in early MM but not in individuals with BMG or in patients with overt $\mathrm{MM}$ is an important one. Indeed, myeloma cells produce IL-1 and/or TNF (11-13). Both cytokines are able to activate osteoblasts $(33,34)$. Osteoblasts produce large amounts of IL-6 $(35,36)$, a potent myeloma cell growth factor $(17,18)$, and bone resorbing factor $(35)$, in response to IL-1/ TNF stimuli. Furthermore, a close cooperation between osteo- blasts and osteoclasts is necessary to initiate bone resorption $(35,36)$. Taken together, these data show clearly that the early osteoblastic recruitment we have presently demonstrated is a critical event in the pathogenesis of human MM. This stimulation could initiate $(a)$ early myeloma cell growth via the production of IL-6, a potent myeloma cell growth factor $(17,18)$, by osteoblasts $(35,36)$. Other cytokines such as granulocyte macrophage-colony stimulating factor (GM-CSF) and IL-3, two other myeloma cell growth cofactors (37) produced by osteoblasts (38), could be involved $(b)$ early excessive bone resorption, via the same factors (IL-6, IL-3, and GM-CSF) involved in the generation of new osteoclasts and bone resorption in synergy with IL-1 and TNF $(35,39-43)$.

A last point deserves some comments. Although it is not recommended to manage subclinical $\mathrm{MM}$ with chemotherapy until overt malignancy (i.e., anemia, bone lesions on radiography) was observed, our data could change this point of view. Furthermore, some bone sparing agents such as diphosphonates could be useful in early MM since they appeared to be beneficial as long-term treatment of mouse plasmacytoma (44) and overt human MM $(45,46)$.

\section{Acknowledgments}

We wish to thank Miss J. Souchon for typing the manuscript and Mrs. L. Zagury-Bataille for editing the English text.

This work was supported by la Ligue Nationale Française contre le Cancer (Paris, France), and la Ligue Régionale contre le Cancer (Clinique Val d'Aurelle, Montpellier, France).

\section{References}

1. Rossi, J. F., R. Bataille, D. Chappard, C. Alexandre, and C. Janbon. 1987. Unusual B cell malignancies presenting unusual bone involvement and mimicking multiple myeloma. A personal study of 9 cases. Am. J. Med. 83:10-16.

2. Marcelli, C., D. Chappard, J. F. Rossi, J. Jaubert, C. Alexandre, P. Dessauw, P. Baldet, and R. Bataille. 1988. Histological evidence of an excessive bone remodeling in B cell malignancies other than multiple myeloma. Cancer (Phila.). 62:1163-1170.

3. Mundy, G. R., L. G. Raisz, R. A. Cooper, G. P. Schechter, and S. E. Salmon. 1974. Evidence for the secretion of an osteoclast stimulating factor in myeloma. N. Engl. J. Med. 291:1041-1046.

4. Valentin-Opran, A., S. A. Charhon, P. J. Meunier, G. M. Edouard, and M. E. Arlot. 1982. Quantitative histology of myeloma-induced bone changes. Br. J. Haematol. 52:601-610.

5. Bataille, R., D. Chappard, C. Alexandre, and J. Sany. 1986. Importance of quantitative histology of bone changes in monoclonal gammopathy. Br. J. Cancer. 53:805-810.

6. Bartl, R., B. Frisch, A. Fateh-Moghadam, G. Kettner, K. Jaeger, and W. Sommerfeld. 1987. Histological classification and staging of multiple myeloma Retrospective and prospective study of 674 cases. Am. J. Clin. Pathol. 87:342355.

7. Gailani, S., W. F. McLimans, G. R. Mundy, A. Nussbaum, O. Roholt, and R. Zeigel. 1976. Controlled environment culture of bone marrow explants from human myeloma. Cancer Res. 36:1299-1304.

8. Durie, B. G. M., S. E. Salmon, and G. R. Mundy. 1981. Relation of osteoclast activating factor production to extent of bone disease in multiple myeloma. Br. J. Haematol. 47:21-30.

9. Josse, R. G., T. M. Murray, G. R. Mundy, D. Jez, and J. N. M. Heershche 1981. Observations on the mechanism of bone resorption induced by multiple myeloma marrow culture fluids and partially purified osteoclast-activating factor. J. Clin. Invest. 67:1472-1481.

10. Rossi, J. F., and R. Bataille. 1984. In vitro osteolytic activity of human myeloma plasma cells and the clinical evaluation of myeloma osteoclastic bone lesions. Br. J. Cancer. 50:119-121.

11. Garrett, I. R., B. G. M. Durie, G. E. Nedwin, A. Gillespie, T. Bringman, M. Sabatini, D. R. Bertolini, and G. R. Mundy. 1987. Production of lymphotoxin, a bone resorbing cytokine, by cultured human myeloma cells. $N$. Engl. J. Med. 317:526-532.

12. Kawano, M., I. Yamamoto, K. Iwato, H. Tanaka, H. Asaoku, O. Tanabe, 
H. Ishikawa, M. Nobuyoshi, Y. Ohmoto, Y. Hirai, and A. Kuramoto 1989. Interleukin I beta rather than lymphotoxin as the major bone resorbing activity in human multiple myeloma. Blood. 73:1646-1649.

13. Gozzolino, F., M. Torcia, D. Aldinucci, A. Rubartelli, A. Miliani, R Shaw, A. R. Lansdorp, and R. Di Guglielmo. 1989. Production of interleukin 1 by bone marrow myeloma cells. Blood. 74:380-387.

14. Bataille, R., D. Chappard, C. Marcelli, P. Dessauw, J. Sany, P. Baldet, and C. Alexandre. 1989. Mechanisms of bone destruction in multiple myeloma. The importance of an unbalanced process in determining the severity of lytic bone disease. J. Clin. Oncol. 7:1009-1014.

15. Bataille, R., D. Chappard, C. Marcelli, P. Dessauw, P. Baldet, J. Sany, and C. Alexandre. 1990. Osteoblast stimulation in multiple myeloma lacking lytic bone lesions. Br. J. Haematol. 76:484-487.

16. Feyen, J. H. M., P. Elford, F. E. Di Padova, and U. Trechsel. 1989. Interleukin 6 is produced by bone and modulated by parathyroid hormone. $J$. Bone Miner. Res. 4:633-638.

17. Kawano, M., T. Hirano, T. Matsuda, T. Taga, Y. Horii, K. Iwato, H. Asaoku, B. Tang, O. Tanabe, H. Tanaka, A. Kuramoto, and T. Kishimoto, 1988. Autocrine generation and essential requirement of BSF-2/IL-6 for human multiple myeloma. Nature (Lond.). 322:83-86.

18. Klein, B. X. G. Zhang M. Jourdan, M. Piechaczyk, F. Houssiau, and R. Bataille. 1989. Paracrine rather than autocrine regulation of myeloma cell growth and differentiation by interleukin-6. Blood. 73:517-526.

19. Kyle, R. A., and J. A. Lust. 1989. Monoclonal gammopathies of undetermined significance. Semin. Hematol. 26:176-200.

20. Bataille, R., J. Grenier, and J. Sany. 1984. Serum beta 2 microglobulin in myeloma: optimal use for staging, prognosis and treatment. A prospective study of 160 patients. Blood. 63:468-476.

21. Bataille, R., P. Delmas, and J. Sany. 1987. Serum bone gla-protein (osteocalcin) in multiple myeloma. Cancer (Phila.). 59:329-334.

22. Frost, H. M. 1976. A method of analysis of trabecular bone dynamics. In Bone Histomorphometry, 2nd Int. Workshop, Lyon. P. J. Meunier, editor. 445470.

23. Chappard, D., C. Alexandre, M. Camps, J. P. Monthad, and G. Riffat. 1983. An embedding process of iliac bone biopsies at low temperature using glycol and methylmethacrylate (GMA and MMA). Stain Technol. 58:299-308.

24. Chappard, D., S. Palle, C. Alexandre, L. Vico, and G. Riffat. 1986. Simultaneous identification of calcified cartilage, bone and osteoid tissue on plastic sections. J. Histotechnol. 9:95-98.

25. Chappard, D., C. Alexandre, and G. Riffat. 1983. Histochemical identification of osteoclasts. Review of the current methods and reappraisal of a simple procedure for routine diagnosis on undecalcified human iliac bone biopsies. $B a$ sic Appl. Histochem. 27:75-85.

26. Palle, S., D. Chappard, L. Vico, G. Riffat, and C. Alexandre. 1989. Evaluation of the osteoclastic population in iliac crest biopsies from 36 normal subjects: a histoenzymologic and histomorphometric study. J. Bone Miner. Res. 4:501506.

27. Parfitt, A. M., M. K. Drezner, F. H. Glorieux, J. H. Kanis, H. Malluche, P. J. Meunier, S. M. Ott, and R. R. Recker. 1987. Bone histomorphometry: standardization of nomenclature, symbols and units. Report of the ASBMR Histomorphometry Nomenclature Committee. J. Bone Miner. Res. 2:595-610.

28. Parfitt, A. M. 1983. Stereologic basis of bone histomorphometry: theory of quantitative microscopy and reconstruction of the third dimension. In Bone Morphometry: Techniques and Interpretation. R. R. Recker, editor. CRC Press, Inc., Boca Raton, FL. 53-87.

29. Chappard, D. 1990. Osteoclast count on human bone biopsies: why and how? In Bone Morphometry. H. Takanashi, editor. Nishimura, Smith-Gordon. 248-255.
30. Beigbeder, M., D. Chappard, C. Alexandre, L. Vico, S. Palle, and G. Riffat. 1988. Improved algorithms for automatic bone histomorphometry on a numerized image analysis system. J. Microsc. (Oxf.). 150:151-160.

31. Canalis, E., T. McCarthy, and M. Centrella. 1988. Growth factors and the regulation of bone remodeling. J. Clin. Invest. 81:277-281.

32. Stashenko, P., F. E. Dewhirst, W. J. Peros, R. L. Kent, and J. M. Ago. 1987. Synergistic interactions between interleukin-1, tumor necrosis factor and lymphotoxin in bone resorption. $J$. Immunol. 138:1464-1468.

33. Thomson, B. M., J. Saklatvala, and T. J. Chambers. 1986. Osteoblasts mediate interleukin 1 stimulation of bone resorption by rat osteoclasts. $J$. Exp. Med. 164:104-112.

34. Thomson, B. M., G. R. Mundy, and T. J. Chambers. 1987. Tumor necrosis factors $\alpha$ and $\beta$ induce osteoblastic cells to stimulate osteoclastic bone resorption. J. Immunol. 138:775-779.

35. Ishimi, Y., C. Miyaura, C. H. Jin, T. Akatsu, E. Abe, Y. Nakamura, A. Yamaguchi, S. Yoshiki, T. Matsuda, T. Hirano, T. Kishimoto, and T. Suda. 1990. Interleukin 6 is produced by osteoblasts and induces bone resorption. $J$. Immunol. 145:3297-3303.

36. Gowen, M., A. J. Littlewood, K. Chapman, K. A. Al-Humidan, D. E. Hugues, S. Ralston, L. Aarden, and R. G. G. Russell. 1989. Interleukin 6 production by bone is stimulated by osteotropic agents but does not alter osteoblast activity or bone resorption. $J$. Bone Miner. Res. 4(Suppl. 1):887.

37. Zhang, X. G., R. Bataille, M. Jourdan, S. Saeland, J. Abrams, J. Banchereau, and B. Klein. 1990. GM-CSF synergizes with interleukin-6 in supporting the proliferation of human myeloma cells. Blood. 76:2599-2605.

38. Felix, R., P. R. Elford, C. Stoerckle, M. Cecchini, A. Wetterwald, U. Trechsel, H. Fleish, and B. M. Stadler. 1988. Production of hemopoietic growth factors by bone tissue and bone cells in culture. J. Bone Miner. Res. 3:27-36.

39. McDonald, B. R., G. R. Mundy, S. Clark, E. A. Wang, T. J. Kwehl, E. R. Stanley, and G. D. Roodman. 1986. Effects of human recombinant CSF-GM and highly purified CSF-1 on the formation of multinucleated cells with osteoclast characteristics in long-term bone marrow cultures. J. Bone Miner. Res. 1:227233.

40. Barton, B. E., and R. Mayer. 1989. IL-3 induces differentiation of bone marrow precursor cells to osteoclast-like cells. J. Immunol. 143:3211-3216.

41. Kurihara, N., T. Suda, Y. Miura, H. Nakauchi, H. Kodama, K. Hiura, Y. Hakeda, and M. Kumegawa. 1989. Generation of osteoclasts from isolated hematopoietic progenitor cells. Blood. 74:1295-1302.

42. Kurihara, N., D. Bertolini, T. Suda, Y. Akiyama, and G. D. Roodman 1990. IL-6 stimulates osteoclast-like multinucleated cell formation in long term human marrow cultures by inducing IL-1 release. J. Immunol. 144:4226-4230.

43. Black, K. S., G. R. Mundy, and I. R. Garrett. 1990. Interleukin-6 causes hypercalcemia in vivo and enhances the bone resorbing potency of interleukin-1 and tumor necrosis factor by two orders of magnitude in vitro. J. Bone Miner. Res. 5(Suppl. 2):787.

44. Radl, J., J. W. Croese, C. Zurcher, M. H. M. Van den Enden-Vieveen, R. J. Brondijk, M. Kazil, J. J. Haaijman, P. H. Reitsma, and O. L. M. Bijvoet. 1985. Influence of treatment with ADP-biphosphonate on the bone lesions in the mouse 5T2 multiple myeloma. Cancer (Phila.). 55:1030-1040.

45. Delmas, P. D., S. Charhon, M. C. Chapuy, E. Vignon, D. Briancon, C. Edouard, and P. J. Meunier. 1982. Long-term effects of dichloromethylene diphosphonate (C12 MDP) on skeletal lesions in multiple myeloma. Metab. Bone Dis. \& Relat. Res. 4:163-168.

46. Merlini, G., G. A. Parrinello, L. Piccinini, F. Crema, M. Fiorentini, A Riccardi, F. Pavesi, F. Novazzi, V. Silingardi, and E. Ascari. 1990. Long-term effects of parenteral dichloromethylene bisphosphonate $\left(\mathrm{Cl}_{2} \mathrm{MBP}\right)$ on bone disease of myeloma patients treated with chemotherapy. Hematol. Oncol. 8:23-30. 